\title{
Understanding Stakeholders' Views and the Influence of the Socio-Cultural Dimension on the Adoption of Solar Energy Technology in Lebanon
}

\author{
Houda Elmustapha ${ }^{1, *}$, Thomas Hoppe ${ }^{2(10)}$ and Hans Bressers ${ }^{1}$ \\ 1 Department of Governance and Technology for Sustainability (CSTM), Institute for Innovation and \\ Governance Studies (IGS), Faculty of Behavioural, Management and Social Sciences (BMS), \\ University of Twente, 7500 AE Enschede, The Netherlands; j.t.a.bressers@utwente.nl \\ 2 Organization and Governance (OG), Department of Multi-Actor Systems (MAS), Faculty of Technology, \\ Policy and Management (TPM), Delft University of Technology, Jaffalaan 5, 2628 BX Delft, The Netherlands; \\ T.Hoppe@tudelft.nl \\ * Correspondence: h.elmustapha@utwente.nl
}

Received: 24 November 2017; Accepted: 19 January 2018; Published: 31 January 2018

\begin{abstract}
In light of climate change and global commitments, a great amount of programs and policies have been implemented by governments targeting the diffusion of renewable energy technologies. Successful diffusion relies on the understanding, persuasion and acceptance by consumers and other stakeholders. This article investigates the views, roles and influence of stakeholders on the adoption of solar energy technology in Lebanon. The main research questions are: What are the stakeholders' views, roles and influence on the diffusion process of solar energy technologies? And are specific socio-cultural factors therein that influenced adoption? The influence of different stakeholders (end users, public representatives, banking sector, suppliers, consultants and NGOs) was assessed via qualitative data analysis, in particular semi-structured interviews. Our research perspective combines grounded and critical theoretical approaches with a case study research design allowing for a semi-inductive process to elaborate and complement new insights to the current body of literature on adoption of clean technology innovation, with a particular focus on the socio-cultural dimension. The results show that contextual factors, specifically related to the social, cultural, geographic and market dimensions, played a crucial role in shaping market development, especially in relation to the uptake of solar energy technology by different consumer groups. Based on the results of this study we argue that more scholarly attention should be awarded to the influence of the socio-cultural dimension and stakeholders' perspectives on adoption of renewable energy technology.
\end{abstract}

Keywords: renewable energy; solar energy; diffusion; innovation-adoption; stakeholders; Lebanon

\section{Introduction}

The rapid growth in global energy demand, alongside the decrease in gas and oil reserves and the problem of the global warming, has led many countries to formulate policies to promote the uptake of renewable energy technologies. Developing countries, however, face many problems to do so. They often suffer from a lack of resources, a dearth of political will and challenging national priorities that prevent the establishment of facilitative action [1]. This article presents a case study on innovation adoption of solar energy technologies (i.e., solar thermal systems and solar photovoltaics in this study) by households and business firms in the developing Middle Eastern country of Lebanon. This choice reflects the fact that solar energy technologies have a large potential in the country, given its rich solar resources. Although national government and donor initiatives contribute to the diffusion of renewable energy technology in developing countries such as Lebanon, consumers play a crucial role in the process by actual deciding whether to adopt or not [2]. 
In August 2010, the Lebanese government became the first Arab country to develop an action plan for energy efficiency and renewable energy of its own [3] — entitled NEEAP. It aimed to achieve a goal of $12 \%$ renewable energy by 2020 through various initiatives and actions by the national level. Support for solar water heaters (SWHs) and solar photovoltaics (PV) were among the initiatives launched by national government and supported by the United Nations to support establishing projects. The latter were generally funded by international parties.

At the national level, solar energy technologies received subsidies to become more attractive to end users. For instance, SWH entailed one of the most mature renewable energy markets in Lebanon [4] and was said to lower the total electricity bill for a typical Lebanese household by up to $25 \%$ [5]. Globally, SWH is seen as one of the most popular solar thermal systems. It accounts for $80 \%$ of the solar thermal market world-wide [6]. Due to the unique conditions of Lebanon, solar PVs are also increasing in importance as an option for citizens to overcome the shortfalls of power supply from the utility grid and without having to revert to costly local diesel generators [7].

We argue that socio-cultural factors are of great importance in understanding the innovation diffusion process of clean technologies like SWH and PV. We believe that by understanding socio-cultural aspects in a regional context, a stronger and richer understanding will be developed of the dynamics shaping the policies and transformation strategies to foster solar energy technology adoption [8]. Previous studies have much ignored the importance of the end users' needs and socio-cultural perspectives [9]. Due to the multidimensional nature of technology adoption, a difference in rates of adoption of technology can occur as a result of, not only economic and technological factors but also of socio-cultural factors [10]. For instance, Qian and Yin (2017) argued that instrumental attributes may not be the most crucial factors for adoption of sustainable innovations [11]. Instead, other environmental, symbolic, or innovative aspects may be more important to consumers [12]. This means that technology adoption may reflect various dimensions, including socio-cultural and situational differences.

The purpose of this study is to explore the role of socio-cultural aspects next to other technical and economic aspects in the adoption of solar energy technologies. Therefore, we will explore the views, roles and influence of various stakeholders' groups in the solar energy market in Lebanon and reflect on adoption from a contextual and socio-cultural point of view. This article addresses two main research questions: (1) What are the stakeholders' views, roles and influence on the diffusion process of solar energy technologies in Lebanon? And (2), what are the specific socio-cultural factors therein that influence adoption? To answer these questions, this study combines grounded and critical theoretical approaches with a case study research design allowing for a semi-inductive process to elaborate and complement new insights to the current body of literature on adoption of clean technology innovation, with a particular focus on the socio-cultural dimension. In doing so two types of end users are addressed: (i) individual households (in the residential sector), and (ii) business firms owning buildings to which solar energy technologies can be applied.

This article is structured as follows. Section 2 presents key conceptual insights on innovationadoption of renewable energy technologies, and the role of socio-cultural factors therein. Section 3 presents the research design and methodology of this study. In Section 4, the results of the case study are presented. Next, in Section 5, the results of the empirical study positioned against the theoretical claims introduced in Section 2. The article ends with a concluding section (Section 6), that includes recommendations for future research.

\section{Theoretical Background on the Diffusion of Renewable Energy Technology}

In this section, we present the "Diffusion of Innovation" (DoI) [2] as a main theory to understand diffusion of clean energy innovations. We address its benefits and shortcomings, and pay special attention to specific technology related and socio-cultural dimensions. 


\subsection{Diffusion of Innovation}

DoI (Rogers, New York, NY, USA, 1962) is considered an academic milestone in the field of novel technology adoption diffusion. Rogers [2] argues that opinion leaders and change agents play an influential role in diffusing innovation within communities through their social network. In addition, this theory [2] explained that when innovations are presented to the public, the public will experience uncertainty when deciding whether to adopt or not. As a result of this uncertainty, potential adopters will engage in information seeking behaviour to assess the necessary factors (innovation characteristics or social factors) before adopting. This is contested by scholars who argue that sharing information alone is not sufficient to initiate behaviour change in communities [13].

\subsection{Limitations of the Diffusion of Innovation Theory}

In various studies DoI was used as an analytical framework focusing on innovation-diffusion of energy efficient systems in residential sector communities (e.g., [14-16]) and in the industry and built environment (e.g., $[17,18])$. Although widely used, the DoI theory is not without limitations. An important limitation is when major socio-cultural factors in the value system of end users and technology specific constraints are not considered.

Given the fact that renewable energy innovations are perceived by many stakeholders as "new" [19], it is likely that some uncertainty surrounds this topic. To capture this, several empirical studies provided insights on how stakeholders view the renewable energy initiatives and what aspects of the innovations may still need to be addressed to influence consumers to adopt renewable energy technologies. For instance, Urmee [1] mentioned that the level of complexity associated with adopting a specific technology varies between countries in the developed world and those in the developing world. This was primarily based on the different level of understanding of a certain technology, individuals' socio-economic status and a set of cultural dimensions. Since the value system of potential adopters is critical to understanding innovation-diffusion and there appears to be a knowledge gap in the innovation-diffusion literature in addressing cultural characteristics [10,20], it is urgent to explore when and how socio-cultural factors influence the innovation-diffusion process.

Several studies have discussed stakeholders' influence on innovation diffusion of clean technologies in a qualitative manner. Berardi [21], however, argues that only little attention has been given to stakeholders' influence on the adoption of energy-saving technologies. Others argue that strong support from engaged stakeholders, on some occasions, seems to stimulate this [22,23].

In the following sub-sections, we discuss the factors found in empirical studies that explain for adoption of renewable energy innovations.

\subsection{Technology Attributes}

People are more likely to adopt an innovation when it has a relative advantage over alternatives; i.e., that it is found superior or better than the idea that it supersedes [2,24]. Caird et al. [25] and Caird and Roy [26] found that the main drivers for adopting micro generation technologies were (perceived) energy savings and lowering of fuel bills. The main barriers were uncertainty about reliability of the technology and performance, long payback periods, high system costs and limited roof space in multi-story buildings.

Silk et al. [24] deduced that if stakeholders did not value renewable energy than adoption would be less likely to occur. Compatibility of innovations, such as solar energy technologies, with personal values [16] and needs, existing practices (operational/practical) [27] or infrastructure [28] were also considered important to innovation-diffusion.

Another important predictor to innovation-diffusion would be complexity, which concerns the extent to which an innovation was difficult to understand and use [2]. Thus, if a technology is viewed by stakeholders as complex, it becomes less likely to be adopted by them [24]. 
Trialability is the degree to which an innovation can be tested on a limited scale [2]. Regarding this predictor, Silk et al. [24] assumed that the absence of the opportunity to test an innovation might decrease the likelihood of adoption. However, at the individual level, trialability was difficult to implement based on the financial costs associated with the renewable energy systems [16].

Finally, observability concerns the degree by which the results of an innovation are visible to potential adopters [2]. Observation by friends, neighbours and family was considered a key motivational factor. Silk et al. [24] explained that if stakeholders were able to observe a renewable energy innovation that was used elsewhere, they might be more comfortable with the idea of adopting the innovation themselves.

\subsection{Market and Financing Incentives}

In their research, Pinkse and Dommisse [29] and Comodi et al. [30] found that the local government was seen as powerful enough to influence the adoption of energy-saving technologies through implementing tight norms to create the conditions in which adoption was encouraged. For instance, Murphy [31] stated that when regulations were missing, then the uncertainty of a specific situation increases, leading to barriers to the adoption of energy-saving technologies. The motives for adopting a clean energy technology not only depended on the technology performance or regulations but also on other factors relative to end users, such as social and socio-economic ones.

In addressing the factors behind the diffusion of solar energy use for hot water systems, several authors [25,26,32] found that financial incentives are important drivers for households to adopt SWH systems. Although financial incentives are often favoured in policy to promote the use of renewable energy technologies, they are certainly not the only important influential driver [33]. Non-financial aspects are also of great importance. Moreover, the non-financial aspect of policy implementation is associated with marketing strategies and consumer trust in sponsoring incentive programmes.

\subsection{Socio-Cultural Factors}

Several behavioural researchers found that non-financial factors influence household renewable energy adoption and use. For instance, values and environmental self-identity strengthen awareness of energy issues and lead to consequences in households' action and create a feeling of moral obligation to energy problems [34,35]. Face-to-face interactions, users' feedbacks and community approach strategies have proven themselves to be effective models to achieve desired actions [36,37].

Mulugetta et al. [38] found that sustainable energy development programmes required multi-faceted intervention that was well-coordinated beyond the donor commitment period. Once technologies were installed, their operation and maintenance became the responsibility of the community or users, who could or may not always want to pay for it [39]. Poor or inappropriate communication with users can also form an important social barrier in the innovation-diffusion of solar heating systems [40]. According to DeCanio [41] diffusion failure often happens for the reason that decisions are always socially embedded and strongly influenced by cultural, personal and institutional constraints that oppose adoption.

In researching the implementation setting of renewable energy technologies a major methodological problem is to systematically evaluate and compare cases in different regions, while taking into consideration levels of technology, economic conditions and cultural influences [8]. Thus mentioning that the relationship between socio-cultural characteristics and renewable energy technology adoption remains under-researched [1].

\section{Contribution of Socio-Cultural Factors}

Different factors play a role in renewable energy technology diffusion, yet integrating the social, cultural dimension along with DoI, technology and policy dimensions will present a rich and comprehensive contribution to explain innovation-diffusion to a larger extent. Shortall and Kharrazi [8] addressed this by saying that through understanding the cultural dimensions of a region, policy makers 
will be able to better address the risks and challenges with on-going stakeholder engagement in decision-making processes. The cultural dimension—although seen as a critical perspective-therefore, needs to be combined with other dimensions to successfully address innovation-diffusion challenges. For instance, Disli [42] and Eseonu and Egbue [10] supported the idea that culture might act as a helpful dimension for policy makers to further understand (and contribute to problem definition within policy making processes) and trigger renewable energy technology adoption, which, in turn, can support lowering carbon emissions.

\section{Methods}

This section presents information on case selection, data collection and data analysis for the case study of the solar energy market in Lebanon. Lebanon presents a unique case study given its geographic location, abundant solar resources and deficiency of conventional energy resources. Despite its positive geographic and climatic conditions, Lebanon has a hostile environment to green innovations associated with its political and the economic instability [43]. The national initiatives implemented in the country demonstrate stakeholders' involvement and interests in the initiatives implemented and their influence on market development.

In this study, special attention is paid to the views and influence of relevant stakeholders. The perspective taken mixes grounded and critical theoretical approaches with a case study allowing a semi-inductive process to build on and complement new insights in the existing literature. This approach allows us to explore comprehensive issues, phenomena and insights that emerge from analysing a rich set of qualitative data, collected among a large number of stakeholders. It allows us to learn and understand the phenomenon of solar energy technologies adoption through the views and experiences of stakeholders. The study of solar energy technologies diffusion starts from a particular theoretical point of view (Rogers' traditional model) and builds on it to enhance the theoretical frameworks from empirical research and to address important situational factors.

The case study was conducted in a stepwise manner. First, an analysis of multiple information sources was conducted, looking into study reports, memos and documentation. Second, a preliminary list of different stakeholders' groups was identified. Based on this, stakeholder representatives were contacted by telephone to check for availability and, if so, follow-up e-mails were sent to address the focus and relevance of the interview. Once stakeholder availability had been confirmed, face-to-face meetings with interviewees were arranged. All stakeholders' views and perspectives were discussed. Third, the influence of stakeholders and other socio-cultural factors on solar energy technologies adoption was also addressed. For this purpose, a case study approach was adopted to investigate a contemporary phenomenon in its real life context and derive meaningful insights from it [44].

\subsection{Stakeholder Analysis}

Stakeholder analysis has been used as a management and strategic tool for identifying the best strategies for managing other stakeholders, identifying current and future opportunities and challenges and how to handle them [45]. During the diffusion process many stakeholders of different backgrounds interact and influence the adoption decision-making process [46]. De Blois et al. [47] highlighted how the contrasting priorities among stakeholders were viewed as the most common barrier to the adoption of energy-saving technologies.

\subsection{Data Collection and Analysis}

A stakeholder analysis was conducted to generate knowledge about stakeholders involved in the market initiatives so as "to understand their behaviours, intentions, inter-relations and interests and for assessing the influence and resources they bring to bear on decision making or the implementation process" [48] (p. 338). The stakeholder analysis consisted of the identification of the stakeholders' views, interests, their influence on the adoption of solar energy technologies and other experienced barriers. Data collection involved participatory research and in-depth interviews with 30 informants 
across eleven different groups of stakeholders (see Table 1); namely national government institutes, NGOs, banks, contractors, consultants, the public sector and end users. Semi-structured questionnaires were used for in-depth interviewing to provide rich insights for understanding different viewpoints. To enrich our understanding for the solar energy market development, different interviewees belonging to the same stakeholder group were approached. This was based on the experience of each stakeholder in respective projects, either addressing SWHs, or PVs, or both. During the interviews, stakeholders were asked about the factors that triggered the Lebanese solar market, the barriers they experienced, strategies and other stakeholders' influence on the diffusion of solar technologies in the Lebanese market.

Table 1. Stakeholders' roles and views on the solar energy market.

\begin{tabular}{|c|c|c|}
\hline Stakeholders & Roles & Experienced Challenges and Drivers \\
\hline $\begin{array}{l}\text { International Cooperation } \\
\text { Agency (project managers } \\
\text { of projects) }\end{array}$ & $\begin{array}{l}\text { Supports the government in achieving } \\
\text { sustainable goals. Initiates and shapes } \\
\text { the market based on the needs of } \\
\text { the country. }\end{array}$ & $\begin{array}{l}\text { Observes highly bureaucratic procedures when } \\
\text { dealing with government institutions; limited } \\
\text { flexibility in changing grid regulations when dealing } \\
\text { with the national utility provider; highly interested } \\
\text { and conscious private sector end users; uncertainty } \\
\text { from end users, shifting in the areas of the future } \\
\text { funds providers. }\end{array}$ \\
\hline $\begin{array}{l}\text { Consultancy/advisory } \\
\text { agent }\end{array}$ & $\begin{array}{l}\text { Provides advice on the solar energy } \\
\text { systems and proposes areas for project } \\
\text { development. }\end{array}$ & $\begin{array}{l}\text { Lack of coordination between sequential projects; need } \\
\text { for policies to overcome technical installation barriers; } \\
\text { competitive electricity prices. }\end{array}$ \\
\hline Private incubation firm & $\begin{array}{l}\text { Creates awareness and develops } \\
\text { market competencies. }\end{array}$ & $\begin{array}{l}\text { Loss of resources due to repetition of similar target } \\
\text { projects across the country; low coordination with } \\
\text { actors from geographical remote areas; technical } \\
\text { barriers in connecting to the national grid; need for } \\
\text { continuous awareness of the public. }\end{array}$ \\
\hline $\begin{array}{l}\text { Providers of solar energy } \\
\text { technologies }\end{array}$ & $\begin{array}{l}\text { Manufacture/import and sell solar } \\
\text { energy systems to the market. }\end{array}$ & $\begin{array}{l}\text { High competition between actors to take part in } \\
\text { internationally funded projects; consumer uncertainty } \\
\text { and financial commitments; changing end users views } \\
\text { and attitudes takes too long. }\end{array}$ \\
\hline NGOs & $\begin{array}{l}\text { Create awareness and collaborate with } \\
\text { the public needs to tackle challenges } \\
\text { in renewable energy markets. }\end{array}$ & $\begin{array}{l}\text { Need for financing methods for poor end users; low } \\
\text { technical knowledge of end users. }\end{array}$ \\
\hline Research institute & $\begin{array}{l}\text { Calls for regulations and policies that } \\
\text { serve market development. }\end{array}$ & Lack of availability of continuous stable funding. \\
\hline $\begin{array}{l}\text { Consumers (e.g., } \\
\text { households, corporate) }\end{array}$ & $\begin{array}{l}\text { Purchase and use solar energy } \\
\text { systems. }\end{array}$ & $\begin{array}{l}\text { High investment costs of solar PV systems; reduction } \\
\text { of energy costs; existing conventional means for energy } \\
\text { and water heating options. }\end{array}$ \\
\hline $\begin{array}{l}\text { National consultancy } \\
\text { agency }\end{array}$ & $\begin{array}{l}\text { Monitor and maintains a } \\
\text { well-developed market through } \\
\text { coordinating between major market } \\
\text { actors and the government while } \\
\text { implementing regulation. }\end{array}$ & $\begin{array}{l}\text { A well-developed market with large numbers of } \\
\text { technology suppliers and supportive } \\
\text { financing schemes. }\end{array}$ \\
\hline $\begin{array}{l}\text { Public sector institutes } \\
\text { (ministry, research centres, } \\
\text { technical institute) }\end{array}$ & $\begin{array}{l}\text { Develop action plans and plan for } \\
\text { policies to support the diffusion of } \\
\text { renewable energy technologies. }\end{array}$ & $\begin{array}{l}\text { Lack of policy focus; country prioritized plans; low } \\
\text { coordination between institutions. }\end{array}$ \\
\hline Financing institutes & $\begin{array}{l}\text { Provide loans for end users to install } \\
\text { and operate their own solar energy } \\
\text { systems. }\end{array}$ & $\begin{array}{l}\text { Demand fluctuates across regions depending on the } \\
\text { client profile, lengthy loan procedures and difficulty in } \\
\text { pushing green technologies in market, constructive } \\
\text { support from the national consultancy agency. }\end{array}$ \\
\hline Educational units & $\begin{array}{l}\text { Provide knowledge and technical } \\
\text { expertise to the public. }\end{array}$ & $\begin{array}{l}\text { Lack of available resources for research and } \\
\text { development; bureaucratic procedures for developing } \\
\text { education material; availability of young local talents } \\
\text { who are technically knowledgeable about solar } \\
\text { energy systems. }\end{array}$ \\
\hline
\end{tabular}

Interviews were conducted face-to-face. Interviews were recorded and transcribed into text files, which were later used for data treatment and analysis using CAQDAS (Atlas.ti). This data treatment 
used a coding scheme consisting of codes resembling the theoretical concepts presented in Section 2 and codes emerging from insights derived from the available data itself. This permitted a more in-depth representation of the situational dimensions from the case study without being limited to specific theoretical notions.

This was followed by a qualitative research approach to look for emerging themes. In a few cases, this led to the desire to contact more experts. Hence, a "snowball method" was applied to retrieve additional informants who could serve as interviewees and provide additional documents for the analysis. In addition, the primary researcher of this study (first author of this article) also participated in meetings for one of the solar energy acceleration projects (SHAAMS). The main topic of this was about the challenges facing solar energy, finding possible solutions to address them and organizing activities (shared between local and foreign actors) to overcome such challenges. Data collection was conducted in two stages, from March to April 2015 and from February to July 2017 (with the same group of stakeholders; yet with different representatives). The selection of experts was based on their involvement in specific solar energy projects. By doing so, the study addressed the evolution of major stakeholders' views, how their interests could be identified and how any changes occurring in the market could be addressed. This would provide a rich understanding of the situation and the socio-cultural and other factors influencing adoption decision-making.

\section{Results}

Table 1 presents an overview of the stakeholders' roles and their views regarding the adoption of solar energy technologies. Since this study focuses on exploring the role that socio-cultural, technical and economic aspects have in the adoption of solar energy technologies, in the next section, barriers experienced by stakeholders relevant to each of these aspects will be discussed in more detail.

\subsection{Technology Attributes and Investment}

When discussing the relative advantages of solar energy systems over non-renewable sources, the end users (i.e., households and decision makers in business companies) mainly focused on the economic benefits of these systems. For instance, this was illustrated by a hotel owner who stated, "end users experience high uncertainty in the country due to unstable economic and safety issues." In this case, end users view investments with high payback periods as particularly risky. This uncertainty makes potential users cautious to engage in long-term investment, since they are more concerned with short-term issues, which appears to be related to unstable lifestyles in the country. The unreliable utility grid and the absence of formal feed-in-tariff schemes also influence the high investment cost of the PV systems. A project manager in an internationally funded project (and technology supplier) illustrates this in the following quote:

We developed a report to show in numbers how much investors are saving their growth rate and size of investments. We use this report to market the benefits of solar PV. It gives people numbers to trust, because there is a lot of scepticism on this in Lebanon ... many of the industries we are working with wouldn't have invested if it were not for the financial incentive (low interest loan) provided to them.

While discussing the compatibility of energy technologies, stakeholders often reflected on how congruent the solar energy technologies are with end users' lifestyles. Banks and technology suppliers are acting as energy advisors for consumers to persuade them to adopt by identifying what types of technologies are required to satisfy the needs and what complementary energy efficient actions are required to lower their energy consumption.

However, the advice was not always taken into consideration by end users, especially in the long run. The main reason for this was that end users might prioritize other investments that they deem more important to their lifestyle and commitments. The advice and close relations formed between suppliers and the end users influenced the latter's satisfaction with the service provided by the former 
and the commitment to spread via positive word-of-mouth communication. Thus, when end users became better informed about the pros and cons of a solar system and about possible technical designs that fit their circumstances, the likelihood would increase that they embrace the uncertainty they have when making investment decisions.

Due to the nature of the solar systems (visible on rooftops), end users (on both the household and corporate firm level) reported on the importance of observability of solar panels. For instance, end users coming from suburban or rural areas (such as villages in the Koura area) indicated that social interaction next to observability could be seen as an important factor influencing adoption decision-making. Through social interaction, potential consumers established a strong desire to obtain feedback on the performance of the solar energy system before making the decision to adopt. This relates to potential consumers basing their decisions on the trialability of solar systems by others and concerned services offered by the same technology supplier. This was based on (positive) experiences they had (i.e., financially and on technical performance).

Although trialability did not have a major impact on the uptake of the technologies, technology suppliers were offering the option of installing trial solar PV panels in order to handle the uncertainties end users have with certain functions of solar energy systems. Thus, customers would not only have the opportunity to try and use the solar energy system but also to form commitment and build trust toward the technology supplier. A technology supplier commented:

We always try to prioritize what the client wants. We offer advice and we offer a trial system for a short time to check its efficiency and if performance lives up to the expectations.

Interviewees also mentioned that the mentality and behaviour of end users was hard to change. This can be observed by the following quotes made by an energy consultant:

While interacting with various households, I often notice that most of them have the habit of turning on the conventional water boiler while the electricity is provided from private generators-using fixed monthly fees-based as a supplement of the national utility grid (due to frequent shut down of the latter). So, they have the attitude of making optimal use of the subscribed amperes they are entitled to use following the energy contract they have. This means that they have no motivation to install SWHs.

In this case, it became competitive to convince end users to switch to a solar energy technology at the time that they are making use of an available option (conventional electricity). Technology suppliers suggested that it is easier to convince organized community groups initiatives when promoting the technology. Interacting with one representative from a village who has the relations and power to find a funder and reach out for end users can do this. Although householders consider the option of purchasing a solar energy system, the prioritization of other financial commitments often delays the decision. The financial concern of middle-income households fluctuates based on other crucial life commitments. A technology supplier exemplifies this:

I interact with a large number of clients and through contact with them I often hear comments that they delay the purchase of a SWH for a certain time when they have less (other) financial commitments. For instance, our sales decrease when schools' curricula start and holiday periods commence. However, they increase in summer.

This example sheds light on the impact of age and family life cycle on decision-making by householders. Similarly, education and educational specialization (i.e., engineering, environmental specialization) also influence the propensity of end users to adopt technologies, especially that of innovativeness. One of the commercial end users commented on this as follows:

I have an engineering background and I am interested in renewable energy technologies. I even considered installing a wind turbine for my factory but settled for a collective PV system. 
To tackle problems regarding investment, available roof space and other barriers, a few interviewees mentioned the importance of establishing trust among the community and embracing the individualistic culture among citizens. As suggested by one of the project managers of an international funded project:

In the future solar PV development should be brought to a new level; for instance, by making collective investments among citizens in local communities.

Another interviewee (a project manager) mentioned the future plans of paving the way for community initiatives through working on a community net metering project locally and striving to scale it country-wide.

\subsection{Market Performance}

Due to the relatively high cost of solar energy systems, stakeholders mentioned the importance of financial incentives in the market, which promote change and influence actions among households and commercial end users of solar systems. However, the efficiency of the incentives depended on how the funding programme was implemented. According to the interviewees, it was important that the financing scheme also took into consideration the needs, lifestyles and living conditions of the consumers. The end users' opinion on the financing scheme varied based on the ways they approached it, the perception of the funding institution, the level of the cognitive effort to the incentive received, trust in the technology provider, and trust in the performance of the solar energy systems supplied. As a result, end users preferred to substitute financing incentives (i.e., a one-on-one procedure with a technology supplier), as they perceived that the government-financing scheme would not be worth the effort, especially in relation to small-sized systems.

Furthermore, the implementation of the financing mechanism exposed some flaws. For instance, it did not take different social (user) groups into consideration, as it was designed to fit individuals of certain employment status and income level. An NGO representative exemplified this:

If we didn't contribute ourselves with our own money to guarantee these un-bankable end users, they could have never received the loan.

Interviewees mentioned that the demonstration projects were found to have created awareness and improved technical talents and created jobs in the renewable energy market. For instance, the technology suppliers were interested in having a role in the demonstration projects to acquire technical knowledge, to achieve higher market status and to interact with potential funders; all these being considered useful to acquire future projects. In addition, technology suppliers formed alliances with foreign importers. This is illustrated by the following quote from a technology supplier:

The UNDP managed projects are seen as good references for us. They were very helpful to provide knowledge; especially in the sense that they provide training sessions and information on the design of the projects which we submit to them. In other words, it is a bidirectional learning process. We are a new company and we lack knowledge in certain areas. So UNDP managed to realize projects and acted as consultants to us.

All interviewed suppliers and project managers mentioned the term 'foreign' when they wanted to show a higher quality of workshops and training sessions on offer. For instance, several corporate stakeholders (such as technology suppliers and project managers) stated that the quality of knowledge shared in training sessions and workshops can be increased via relationships with foreign technical experts and partnerships with foreign technology suppliers. Importing products from certain Western countries that are seen as leaders in solar energy markets (i.e., Germany and Italy) were perceived to give a certain advantage. This also holds for technology suppliers who seek to acquire a certain market status through marketing their products in specific countries that are considered leaders in solar energy technology. This is illustrated by a quote from a solar PV supplier: 
We work with European technology suppliers and interact with the German market for monitoring systems and inverters, since most of our clients have the opinion that by acquiring European products they get guaranteed high quality.

\subsection{Socio-Cultural Factors}

Diffusion is best achieved when a set of different factors are combined. For instance, sometimes the driver to adopt a new technology might not only be technical or economic in nature but also social and cultural [49].

Most stakeholders mentioned the importance of participation, information sharing and transparency as important factors triggering change and having a positive impact on end users' engagement in renewable energy technologies.

Few stakeholders observed the individualistic nature of the citizens, which, to some extent, created a social challenge for integrating the collective solar PV system concept (e.g., a large group of end users sharing one large scale solar PV system) into the market. This explains why individuals prefer to have autonomous control and take care of their own needs. The householders experienced a lack of trust in other citizens (for instance, between neighbours who are mutually dependent when constructing a collective solar PV system to a residential building) and a collaborative spirit hardly existed. This occurred, in particular, in urban areas where busy lifestyles go along with low rates of social interaction between residents. Therefore, a possible solution to this challenge could be by introducing community initiatives and collective concepts in villages deemed to have a good chance of becoming successful.

This is exemplified by the following quote by a technology supplier in a Lebanese suburban area:

Here in the village people influence each other especially when someone installed a SWH and is satisfied; they immediately spread positive words-of-mouth.

The reasons behind this are strong social ties and a sense of belonging to a large social group. Therefore, in this case, the social influence strategies, which target non-financial factors, resulted, to a certain extent, in higher adoption rates. Strategies, such as face-to-face interactions, that included community approaches and a commitment to strategies of actions were considered particularly effective.

Another dimension that was viewed by stakeholders to define and trigger the solar energy market concerned public investment actions. This is, to a certain extent, embedded in the social norms of Lebanese society. When the key stakeholders (i.e., the national consultancy agency, the international agency, or ministries) in the renewable energy market launched the first SWH initiative, massive investments were made. Although this entrepreneurial growth contributed to economic development, it faced various challenges that led to negative views spread by word-of-mouth about the SWH systems. The challenges were classified as the absence of quality control schemes, which resulted in low quality products with poor installation. In a later stage, the financing schemes indirectly improved quality of products in the market through grant provision for end users, based on specific qualified solar energy systems.

A noticeable factor among all interviewees was the transnational influence of acquiring expertise and knowledge from specific developed countries that served as role models. This could be explained by the culture in which citizens live and in which they accept a high degree of hierarchy. Every person in the Lebanese society has a particular role and status in the society. This also applies to inter-actor behaviour of actors in the solar energy market.

Interestingly, end users (i.e., households and companies) were using a similar approach to create a certain public image. Some of them only requested solar energy systems from specific countries to reflect their social identity and preferences regarding high quality assurance of the product, especially those having long life spans. This, in turn, reflected the importance that social 
status has at the household level and also on the corporate level, especially among decision makers who are in continuous contact with other stakeholders in the society.

Several stakeholders mentioned the geographical dimension, which includes social, cultural and economic dimensions. Based on the empirical evidence from the solar energy market in Lebanon, various differences between the cities located in North Lebanon and cities Central Lebanon were discussed. The stakeholders mentioned that end users Central Lebanon have a relatively higher income level and, to some extent, higher living standards influenced their lifestyles. Approaching end users in rural areas mainly took place via social interaction and word-of-mouth. However, approaching end users living in the more urbanized (often hectic and densely populated) cities required different marketing approaches. In these circumstances, technology suppliers are investing to create a certain market identity through involvement in funded projects and connecting with prospective funders. Consumer mentality, lifestyle and openness differ across regions. Openness and income level influence uptake levels as exemplified in a quote made by an energy consultant and a project manager of an international funded project:

\section{Poor communities are still in need for supportive programs to tackle the renewable energy technologies uptake obstacles.}

This is also true for the networking activities between stakeholders. Most of the workshops and activities were centralized and mainly took place in the country's capital and cities in its close proximity. This affected the integration of stakeholders from relatively far regions in the activities and the amount of information shared. Actors from these more distant regions often felt isolated. They felt a need to make a lot of effort to keep continuous interaction with active solar market stakeholders and efforts in the capital.

Geographic area was said to influence interaction with potential consumers. This was exemplified in the following quote made by a technology supplier:

The interaction between us and the clients differ across regions. For instance, in a centralized region (i.e., in Beirut and its suburbs) people have a busier lifestyle and therefore often do not have the time available to visit technology suppliers and have face-to-face communication with them. Most the interactions are either by phone or by email. Yet, here in Tripoli (a large city in North Lebanon) clients prefer to make a visit to our company and check the available systems.

\section{Discussion}

The analysis of stakeholders' views revealed that there is more innovation diffusion than that expected in the DoI theory.

According to Rogers [2], end users tend to look at the immediacy of the reward in relation to relative advantage; while the reward of certain innovations is not expected to occur immediately. The interesting advantage that was discussed by most interviewees (covering most of the stakeholders' variation) was the idea that the long-term benefits of solar energy systems outweigh the short-term costs. The national financing scheme proved to be successful in increasing the adoption rates across multiple economic sectors. However, we agree with Reddy and Painuly [50] that the policy makers have to choose the right type of financing schemes, while also taking into consideration the local needs and traditions of citizens in society. This means, for instance, coping with the demand for specific renewable technologies that need to comply with the available challenges (e.g., PV systems with batteries, collective available funds to tackle challenges, or funds for poor households with limited financial-economic capabilities).

Therefore, in the case of solar PVs and collective solar energy systems, the long payback period associated with the high uncertainty embedded in the country creates a challenge for their uptake. We agree with Silk et al. [24] that introducing the perception that the good of society outweighs the needs of the individual can overcome on-going uptake challenges and lead to social and economic benefits. However, due to the individualistic nature of many citizens, such a concept is challenging. 
We argue that the results of our study contribute to the results of a study by Shortall and Kharrazi [8] and Urmee [1] who came across a knowledge gap in diffusion of innovation research regarding social and cultural factors. Our result show that the individualistic nature of the end users in society is challenging the innovative solutions around issues such as handling roof space availability and making high upfront investment costs. Furthermore, the perception of acquiring a 'foreign' product is strongly linked to the mind-set of the potential users, who are typically considered as having high social status in their identity among other end users. This is mainly characterized by the propensity of the individuals to 'show off' in their social environment, where acquiring eye catching radical innovations is considered one of the ways to do so.

Uncertainty, compatibility, complexity and perceived benefits appear interrelated when it comes to the uptake of solar energy technologies. The complexity associated with the installation of solar systems on the limited roof spaces available, the requirement for long pipelines for high story buildings (in the case of $\mathrm{SWH}$ ) and the lengthy process of receiving loans, all affect the perception of the solar energy system. These factors had an overarching impact on attitudes and perceived norms [24].

The demonstration projects that took place in the country positively influenced the development of the market. The benefits were not only limited to increasing awareness among the public and building trust in the technologies while removing risk and uncertainties but also created technical knowledge and improved the technical expertise among the local workers. These projects were viewed as trials for the end users from selected industries; such as factories. This helped technology suppliers to improve their expertise and learn from demonstration projects, which, in turn, improved their market status.

We agree with several authors [51-55] on the importance of social influence, particularly the influence of recommendations from friends and neighbours on households' decisions as to whether to adopt solar systems. The interest of end users and stakeholders in reflecting a specific social identity appeared to be of significance in influencing the adoption process [55]. The individualistic culture among households appeared to create a challenge for the collective concept (launching large scale systems for large groups of end users), which is ideal to solve, both the roof space problem and the high investment cost. We also agree that education appears to be linked to the adoption of renewable energy systems. In particular, the type of education specialization; for example, when potential adopters had engineering or environmental backgrounds, this led individuals to be more likely to adopt renewable energy systems than those having other educational backgrounds [56,57].

When addressing the role of technology suppliers, a key element is the customer-value proposition [58]. This defines how organizations can differentiate themselves as competitors and attract and deepen the relationships with the targeted customer groups to build a higher market share. In line with this, we agree that the technology suppliers were engaging with the consumers on the social and personal level to build trust and guarantee strong social benefits. This close relation varies between regions; yet, the satisfaction of the end users results from positive word-of-mouth and low-cost marketing of the adopted technologies.

This study showed the significant role that socio-cultural, technical and economic aspects have in the adoption of solar energy technologies. The results show that the on-going challenges are mainly culturally and economically embedded and require creative solutions that are tailored to the end users' needs and situational circumstances. To result in broad changes in societal discourses challenges in values, behaviours, habits alongside infrastructural, institutional and organizational challenges, need to be addressed. This stresses the need for new policy approaches to address a clear connection to the on-going contextual and situational circumstances, along with the social structures and relevant preferences of local actors. 


\section{Conclusions and Future Implications}

There were two main research questions in this article: (1) What are the stakeholders' views, roles and influence on the diffusion process of solar energy technologies in Lebanon? And (2) what are the main specific socio-cultural factors that influence adoption?

The implementation of demonstration projects in the solar energy field contributed to the market on various levels. It created higher observability and improved the technical experience of installers in the market. Furthermore, it raised awareness among stakeholders and increased trust in the technologies.

As technology-related attributes, such as relative financial advantage, observability and compatibility with values, play a role in shaping the uptake of solar energy technologies, so do social ties between end users and their wider community of friends, family and neighbours, whilst recognising the variations between rural and urban areas. More than this, end user characteristics play a role in adoption of technologies along with their interest in acquiring certain social identity. For instance, the educational level and specialization play a role in promoting the uptake of solar energy technologies at both the household and corporate level.

Regarding the second research question, we provided the following differentiation between households and corporate end users:

1. At the household level-the main findings can be grouped into three categories. First, end user characteristics are important to understand when considering adoption decision-making. The most important are: the income level and how these guarantee access to capital; education; and, to some extent, how family lifecycle settings influence householders' financial commitments and priorities and thus drive the propensity to invest in renewable energy solutions. Second, the costs and benefits of investing in a solar energy system are divided between monetary (the investment cost and savings) and non-monetary aspects (such as comfort and compatibility, which depend on the physical context and cultural expectations of the households). This category deals with the attributes of the technology and also involves the real and perceived risks and uncertainties that play a crucial role in the Lebanese context. Third, a factor that has received less attention concerns the particular geographic influence on the end users. This factor is broad enough not to be limited to just the physical classification of rural and urban areas across different regions. It also includes the intensity of social ties and interaction between end users and other stakeholders (such as technology suppliers), thus reflecting the importance of local and regional networks. Furthermore, the individual openness and mentality of the people tend to vary between different Lebanese regions, shaping the means of interaction between them and the other stakeholders, thus reflecting the rather uneven diffusion patterns.

2. At the corporate firm level-several similarities appear comparable with individuals at the household level, while others remain specific to the corporate level. First, the individual characteristics of the decision maker are important to acknowledge. One concerns how education specialization affects the propensity to adopt when considering renewable energy solutions. Second, the costs and benefits of investing in a renewable energy solution are considered important. This relates to the awareness level of the decision-maker to assess renewable energy solutions so as to reduce the cost of consumed energy and also undertake the appropriate networking and research to find the most convenient investment decision. The third factor concerns the competitive advantage and the market image that a company or organization will acquire in the market. For instance, the adopter will enhance the market image of the corporation through their environmental involvement and responding to a leading attribute in considering innovative solutions. Thus, these will also result in increasing customer attraction to organization values. Furthermore, the social status and public image were found to be important to firms. Various decision makers at the corporate level were concerned about the social identity of their firms and preferred specific foreign high quality products to convey this identity. It revealed the 
importance given to the socio-cultural dimension in marketing strategy in particular, and the adoption process at large.

Due to the autonomous control of consumers over their energy use and the continuous decline in the prices of renewable energy technologies [59], there is a need to shift to performance-based approaches. These approaches will promote the shift from cost of service to the value of service and eventually provide an opportunity for consumers and service providers to meet their goals. This means that consumers will receive rewards based on their energy savings, which motivates their involvement in energy efficient practices and results in lower energy demand on the utility providers.

Looking to future research opportunities, this would be a great opportunity for integrating the socio-cultural dimension with other social and technology-related aspects. In this arena, it is crucial to compare the wide range of dimensions with and between countries when they have different cultures, yet relatively similar economies. By doing so, research into a rich set of independent variables, rather than the DoI, as it is typically applied and psychological variables will be conducted vis-à-vis adoption decision-making of renewable energy technologies.

The results of this study provide a context for understanding the views of various stakeholder groups regarding renewable energy initiatives. Although these data may not be generalized yet, they can be used to guide and inform future qualitative and quantitative research about the adoption of solar energy technologies. Further research tackling behavioural, social, cultural and economic aspects, in relation to the uptake of renewable energy technologies from developing economies, can be applied. Future research should also examine the influence that cultural, social norms and values have on a person's likelihood to adopt a renewable energy innovation.

Acknowledgments: The authors warmly thank all interviewees for giving freely of their time to discuss questions related to the renewable energy market in Lebanon. The authors also thank the Open Access Fund at the University of Twente for providing the budget to publish this article.

Author Contributions: Houda Elmustapha, Thomas Hoppe and Hans Bressers prepared the research design. Houda Elmustapha collected and analysed the data. Houda Elmustapha, Thomas Hoppe and Hans Bressers wrote the paper.

Conflicts of Interest: The authors declare no conflict of interest.

\section{Abbreviations}

The following abbreviations are used in this manuscript:

NEEAP National Energy Efficiency Action Plan

NGO Non-Governmental Organization

SWH Solar Water Heating System

PV Photovoltaics

UNDP United Nations Development Program

SHAAMS Strategic Hubs for the Analysis and Acceleration of the Mediterranean Solar Sector

\section{References}

1. Urmee, T. Social, cultural and political dimensions of off-grid renewable energy programs in developing countries. Renew. Energy 2016, 93, 159-167. [CrossRef]

2. Rogers, E.M. Diffusion of Innovation, 5th ed.; Free Press: New York, NY, USA, 2003.

3. Khoury, P.; Hajj Shehadeh, N.; Chaban, F. The National Energy Effieciency Action Plan for Lebanon. 2011. Available online: http:/ / www.rcreee.org/sites/default/files/plans_neeap_lebanon_2011_en.pdf (accessed on 21 January 2015).

4. Nassab, C. High Rise Buildings and Solar Water Heater Installations; CEDRO: Beirut, Lebanon, 2013.

5. Lee County Electric Cooperative (LCEC). The Residential Solar Water Heaters Market in Lebanon in 2011 How Can Sound Governmenta; Lee County Electric Cooperative (LCEC): Fort Myers, FL, USA, 2012.

6. Wang, Z.; Yang, W.; Qiu, F.; Zhang, X.; Zhao, X. Solar water heating: From theory, application, marketing and research. Renew. Sustain. Energy Rev. 2014, 41, 68-84. [CrossRef] 
7. Harajli, H.; Obeid, J.; Nassab, C. Techno-Financial Appraisal of Roof-Top Photovoltaic (Pv) Systems: The Case of Lebanon; CEDRO: Beirut, Lebanon, 2016.

8. Shortall, R.; Kharrazi, A. Cultural factors of sustainable energy development: A case study of geothermal energy in Iceland and Japan. Renew. Sustain. Energy Rev. 2017, 79, 101-109. [CrossRef]

9. Elmustapha, H.; Hoppe, T.; Bressers, H. Consumer renewable energy technology adoption decision-making; Comparing models on perceived attributes and attitudinal constructs in the case of solar water heaters in Lebanon. J. Clean. Prod. 2018, 172, 347-357. [CrossRef]

10. Eseonu, C.; Egbue, O. Socio-Cultural Influences on Technology Adoption and Sustainable Development. In Proceedings of the Industrial and Systems Engineering Research Conference, Montreal, QC, Canada, 31 May-3 June 2014; pp. 2711-2717.

11. Qian, L.; Yin, J. Linking Chinese cultural values and the adoption of electric vehicles: The mediating role of ethical evaluation. Transp. Res. Part D 2017, 56, 175-188. [CrossRef]

12. Noppers, E.H.; Keizer, K.; Bolderdijk, J.W.; Steg, L. The adoption of sustainable innovations: Driven by symbolic and environmental motives. Glob. Environ. Chang. 2014, 25, 52-62. [CrossRef]

13. Viardot, E. The role of cooperatives in overcoming the barriers to adoption of renewable energy. Energy Policy 2013, 63, 756-764. [CrossRef]

14. Mallett, A. Social acceptance of renewable energy innovations: The role of technology cooperation in urban Mexico. Energy Policy 2007, 35, 2790-2798. [CrossRef]

15. Mahapatra, K.; Gustavsson, L. An adopter-centric approach to analyze the diffusion patterns of innovative residential heating systems in Sweden. Energy Policy 2008, 36, 577-590. [CrossRef]

16. Labay, D.; Kinnear, T.C. Exploring in the the Consumer of Decision Energy Process Adoption Solar Systems. J. Consum. Res. 1981, 8, 271-278. [CrossRef]

17. Dieperink, C.; Brand, I.; Vermeulen, W. Diffusion of energy-saving innovations in industry and the built environment: Dutch studies as inputs for a more integrated analytical framework. Energy Policy 2004, 32, 773-784. [CrossRef]

18. Vermeulen, W.J.V.V.; Hovens, J. Competing explanations for adopting energy innovations for new office buildings. Energy Policy 2006, 34, 2719-2735. [CrossRef]

19. Sovacool, B.K. The cultural barriers to renewable energy and energy efficiency in the United States. Technol. Soc. 2009, 31, 365-373. [CrossRef]

20. Daghfous, N.; Petrof, J.; Pons, F. Values and Adoption of Innovation: A Cross-Cultural Study. J. Consum. Mark. 1999, 16, 314-331. [CrossRef]

21. Berardi, U. Stakeholders' influence on the adoption of energy-saving technologies in Italian homes. Energy Policy 2013, 60, 520-530. [CrossRef]

22. Andrews, C.J.; Krogmann, U. Explaining the adoption of energy-efficient technologies in U.S. commercial buildings. Energy Build. 2009, 41, 287-294. [CrossRef]

23. Lee, T.; Yao, R. Incorporating technology buying behaviour into UK-based long term domestic stock energy models to provide improved policy analysis. Energy Policy 2013, 52, 363-372. [CrossRef]

24. Silk, K.J.; Hurley, A.; Pace, K.; Maloney, E.K.; Lapinski, M. A Diffusion of Innovations Approach to Understand Stakeholder Perceptions of Renewable Energy Initiatives. Sci. Commun. 2014, 36, 646-669. [CrossRef]

25. Caird, S.; Roy, R.; Herring, H. Improving the energy performance of UK households: Results from surveys of consumer adoption and use of low- and zero-carbon technologies. Energy Effic. 2008, 1, 149-166. [CrossRef]

26. Caird, S.; Roy, R. Adoption and use of household microgeneration heat technologies. Sci. Res. 2010, 2010, 61-70. [CrossRef]

27. Tornatzky, L.; Klein, K. Innovation characteristics and innovation adoption-implementation: A meta-analysis of findings. IEEE Trans. Eng. Manag. 1982, 29, 28-43. [CrossRef]

28. Claudy, M.C.; Michelsen, C.; O'Driscoll, A. The diffusion of micro generation technologies-Assessing the influence of perceived product characteristics on home owners' willingness to pay. Energy Policy 2011, 39, 1459-1469. [CrossRef]

29. Pinkse, J.; Dommisse, M. Overcoming Barriers to Sustainability: An Explanation of Residential Builders' Reluctance to Adopt Clean Technologies. Bus. Strateg. Environ. 2009, 18, 515-527. [CrossRef]

30. Comodi, G.; Cioccolanti, L.; Polonara, F.; Brandoni, C. Local authorities in the context of energy and climate policy. Energy Policy 2012, 51, 737-748. [CrossRef] 
31. Murphy, K. The social pillar of sustainable development: A literature review and framework for policy analysis. Sustain. Sci. Pract. Policy 2012, 8, 15-29. [CrossRef]

32. Sidiras, D.K.; Koukios, E.G. Solar systems diffusion in local markets. Energy Policy 2004, 32, $2007-2018$. [CrossRef]

33. Stern, P.C.; Janda, K.B.; Brown, M.A.; Steg, L.; Vine, E.L.; Lutzenhiser, L. Opportunities and insights for reducing fossil fuel consumption by households and organizations. Nat. Energy 2016, 1, 16043. [CrossRef]

34. Stern, P.C.; Dietz, T.; Abel, T.; Guagnano, G.A.; Kalof, L. A value-belief-norm theory of support for social movements: The case of environmentalism. Hum. Ecol. Rev. 1999, 6, 81-97.

35. Steg, L.; Perlaviciute, G.; van der Werff, E. Understanding the human dimensions of a sustainable energy. Front. Psychol. 2015, 6, 805. [CrossRef] [PubMed]

36. Abrahamse, W.; Steg, L. Social influence approaches to encourage resource conservation: A meta-analysis. Glob. Environ. Chang. 2013, 23, 1773-1785. [CrossRef]

37. Steg, L.; Dreijerink, L.; Abrahamse, W. Factors influencing the acceptability of energy policies: A test of VBN theory. J. Environ. Psychol. 2005, 25, 415-425. [CrossRef]

38. Mulugetta, Y.; Nhete, T.; Jackson, T. Photovoltaics in Zimbabwe: Lessons from the GEF Solar project. Energy Policy 2000, 28, 1069-1080. [CrossRef]

39. Murni, S.; Urmee, T.; Whale, J.; Davis, J.; Harries, D. The implementation of micro hydro projects in remote villages on the border of Indonesia and Malaysia: Lessons learnt. In Proceedings of the International Conference and Utility Exhibition on Green Energy for Sustainable Development, Pattaya, Thailand, 19-21 March 2014.

40. Lilefors, P.; Sahlin, J. Drivers and Barriers for Solar Home Systems (SHS) in Rural Communities: A Case Study in Kyerwa. Available online: https:/ / www.diva-portal.org/smash/get/diva2:741679/FULLTEXT01.pdf (accessed on 17 January 2018).

41. DeCanio, S. The efficiency paradox: Bureaucratic and organizational barriers to profitable energy-saving investments. Energy Policy 1998, 26, 441-454. [CrossRef]

42. Disli, M.; $\mathrm{Ng}$, A.; Askari, H. Culture, income, and $\mathrm{CO}_{2}$ emission. Renew. Sustain. Energy Rev. 2016, 62, 418-428. [CrossRef]

43. Thornton, W. Strategic Niche Management of the Solar Electricity Sector in Lebanon; CEDRO: Beirut, Lebanon, 2016.

44. Yin, R. Case Study Research, 5th ed.; Sage Publications: Los Angeles, CA, USA, 2014.

45. Blair, J.; Fottler, M. Challenges in Health Care Management: Strategic Perspectives for Managing Key Stakeholders; Jossey-Bass Publishers: San Fransisco, CA, USA, 1990.

46. Cooke, R.; Cripps, A.; Irwin, A.; Kolokotroni, M. Alternative energy technologies in buildings: Stakeholder perceptions. Renew. Energy 2007, 32, 2320-2333. [CrossRef]

47. De Blois, M.; Herazo-cueto, B.; Latunova, I.; Lizarralde, G. Relationships between Construction Clients and Participants of the Building Industry: Structures and Mechanisms of Coordination and Communication Relationships between Construction Clients and Participants of the Building Industry: Structures and Mechan. Archit. Eng. Des. Manag. 2011, 7, 3-22.

48. Varvasovszky, Z.; Brugha, R. How to do (or not to do)... A stakeholder analysis. Health Policy Plan. 2000, 15, 338-345. [CrossRef] [PubMed]

49. Sharma, B.; Gadenne, D. Consumers' attitudes, green practices, demographic and social influences, and government policies: An empirical investigation of their relationships. J. New Bus. Ideas Trends 2017, 12, $22-36$.

50. Reddy, S.; Painuly, J.P. Diffusion of renewable energy technologies-barriers and stakeholders' perspectives. Renew. Energy 2004, 29, 1431-1447. [CrossRef]

51. Heiskanen, E.; Matschoss, K. Understanding the uneven diffusion of building-scale renewable energy systems: A review of household, local and country level factors in diverse European countries. Renew. Sustain. Energy Rev. 2017, 75, 580-591. [CrossRef]

52. Sopha, B.M.; Klöckner, C.A.; Skjevrak, G.; Hertwich, E.G. Norwegian households' perception of wood pellet stove compared to air-to-air heat pump and electric heating. Energy Policy 2010, 38, 3744-3754. [CrossRef]

53. Palm, J.; Tengvard, M. Motives for and barriers to household adoption of small-scale production of electricity: Examples from Sweden. Sustain. Sci. Pract. Policy 2011, 7, 6-15. [CrossRef]

54. Schelly, C. Testing solar thermal adoption. Environ. Behav. 2010, 42, 151-170. [CrossRef] 
55. Janssen, M.A.; Jager, W. Stimulating diffusion of green products-Co-evolution between firms and consumers. J. Evol. Econ. 2002, 12, 283-306. [CrossRef]

56. García-Maroto, I.; García-Maraver, A.; Muñoz-Leiva, F.; Zamorano, M. Consumer knowledge, information sources used and predisposition towards the adoption of wood pellets in domestic heating systems. Renew. Sustain. Energy Rev. 2015, 43, 207-215. [CrossRef]

57. Karytsas, S.; Theodoropoulou, H. Public awareness and willingness to adopt ground source heat pumps for domestic heating and cooling. Renew. Sustain. Energy Rev. 2014, 34, 49-57. [CrossRef]

58. Kaplan, R.; Norton, D. Transforming the Balanced Scorecard from Performance Measurement to Strategic Management: Part II. Account. Horiz. 2001, 15, 147-160. [CrossRef]

59. Banks, J. Why Performance-Based Regulation is Important for the Electric Utility Transformation. Available online: https: / / www.brookings.edu/blog/planetpolicy/2015/12/03/why-performance-based-regulationis-important-for-the-electric-utility-transformation/ (accessed on 17 January 2018).

2018 by the authors. Licensee MDPI, Basel, Switzerland. This article is an open access article distributed under the terms and conditions of the Creative Commons Attribution (CC BY) license (http://creativecommons.org/licenses/by/4.0/). 